\title{
Obstructive sleep apnoea
}

\author{
Steven G McNamara, Ronald R Grunstein, Colin E Sullivan
}

The last 20 years of respiratory medical practice have seen many changes. As other subspecialties such as oncology, infectious diseases, allergy/immunology, intensive care, and occupational medicine increasingly make inroads into the traditional areas of respiratory practice, new fields requiring the expertise of the respiratory physician have developed. Arguably the dominant examples of these are disorders of breathing in sleep. Until recently terms such as "REM sleep," "apnoea index," and "nasal CPAP" were foreign to most people working in respiratory medicine. The parallel development of methods of measuring ventilation and blood gas levels non-invasively with the standardised monitoring of sleep has led to a recognition that sleep disorders-particularly abnormal breathing during sleep-are both causes and contributors to a broad spectrum of clinical morbidity and mortality.

While researchers and clinicans working in the field agree on the importance of accurate diagnosis and appropriate treatment for patients with sleep breathing disorders, there is considerable disparity in the availability of investigation and treatment for such patients in different countries. In the USA it has been estimated that there is more than one sleep laboratory per 250000 people; in Australia there is at least one per 1000000 , but in the UK the ratio is much lower. While these differences in the availability of facilities may reflect a variation in health care expenditure or structure, it is likely that they also reflect a divergence in the relative importance with which health planners and policy makers view disorders of breathing in sleep. To provide a detailed review of recent advances in the understanding of sleep and breathing disorders requires a monograph. ${ }^{1}$ The purpose of this review is to assess some recent developments in the most common sleep breathing disorder-obstructive sleep apnoea-with particular emphasis on recent data on diagnosis, prevalence, predisposing factors, clinical sequelae, and treatment in the adult patient.

\section{Diagnosis and prevalence}

WHAT IS OBSTRUCTIVE SLEEP APNOEA?

One of the key problems in recognising the importance of obstructive sleep apnoea (OSA) is the lack of a clearly agreed defini- tion. While an apnoea is agreed upon as a cessation of breathing for 10 or more sec- $\overrightarrow{0}$ onds, ${ }^{2}$ there is a wide range in the frequency $\vec{\overrightarrow{ }}$ of such events during sleep; how this frequency (or "respiratory disturbance index") $\overrightarrow{\vec{*}}$ correlates with disease severity and incidence continues to be debated. ${ }^{3}$ Most researchers $\stackrel{\infty}{\stackrel{0}{ }}$ use a working definition of five apnoeas per hour to define sleep disordered breathing ${ }^{2}$ but $\stackrel{ }{\perp}$ this is by no means consistent in the litera- $\frac{\text { O }}{3}$ ture. This definition was developed at a time when OSA was thought to be a rare disorder $\subseteq$ and these arbitrary cut offs allowed $₹$ researchers to communicate in a common $\vec{\varphi}$ "language" - an important consideration in reviewing any literature on this subject. As OSA is increasingly recognised as a common disorder such definitions need to be reconsid- $\bar{\partial}$ ered.

Most clinicians recognise OSA as a dis- $\stackrel{\mathbb{D}}{\varrho}$ order characterised by repetitive apnoeas, $\overrightarrow{\overrightarrow{\vec{A}}}$ loud snoring, and excessive daytime sleepi- 3 ness. However, in OSA the patient is often the last to realise the extent of the mental and? physical effects of the disorder. Recent studies have shown that some forms of OSA may $\frac{0}{2}$ occur without the presence of snoring ${ }^{4}$ or $\times$ apnoea $^{5}$ but with obvious clinical effects. $\frac{\sigma}{3}$ Similarly, excessive daytime sleepiness may not occur but instead the clinical picture may $\frac{0}{3}$ mimic an anxiety state, especially in women. ${ }^{6} \frac{}{0}$ Adult criteria for OSA may also not be appropriate in children. ${ }^{7}$ It is important that the clinical definition of OSA is kept flexible. The individual with one or two apnoeas per hour, $\mathbb{N}$ oxygen desaturation to $60-70 \%$, and $N$ impaired arousal reflexes due to autonomic neuropathy is far more vulnerable to the con- $\overline{0}$ sequences of their $\mathrm{OSA}^{8}$ than a healthy, asymptomatic 75 year old with 15 apnoeas per hour. The epidemiologist or health? administrator may wish for a more rigid defi- $T$ nition of OSA, but until we have a better $\frac{\vec{D}}{\mathbb{D}}$

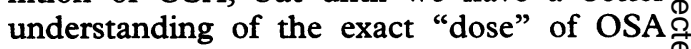

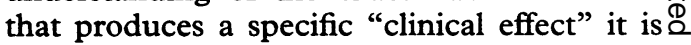
better to avoid such rigidity.

EPIDEMIOLOGY

Epidemiological studies in OSA fall into three categories: firstly, studies based solely on? questionnaire data about habitual snoring, or a history of witnessed apnoeas, or both; secondly, studies in which questionnaires are validated by full polysomnographic sleep studies or nocturnal respiration monitoring in 
Recent epidemiological studies in obstructive sleep apnoea

\begin{tabular}{|c|c|c|c|c|c|c|}
\hline & $n$ & Age (y) & $\begin{array}{l}\text { Study } \\
\text { type }\end{array}$ & Prevalence & Comment & Reference \\
\hline Gislason, Sweden & 3201 & $30-69$ & B & $0.7-1.9 \%$ & Men only & 9 \\
\hline Cirignotta, Italy & 1510 & $30-69$ & B & $2 \cdot 7 \%(\mathrm{RDI}>10)$ & RDI $>10$, men only & 10 \\
\hline Stradling, UK & 893 & $35-65$ & C & $5 \%$ (men) & Oximeter dips per hour $>5$ & 11 \\
\hline Bearpark, Australia & 400 & $40-65$ & $\mathrm{C}$ & $10 \%$ men, $7 \%$ women & $\begin{array}{l}\text { MESAM } 4 \text { recorder } \\
\text { calculated RDI }>10\end{array}$ & 12 \\
\hline Young, USA & 263 & $30-60$ & C & $7 \cdot 8 \%$ men, $2 \cdot 3 \%$ women & $\begin{array}{l}\text { RDI }>10 \text { on full sleep } \\
\text { studies }\end{array}$ & 13 \\
\hline Jennum, Denmark & 1504 & $30-60$ & B & $\begin{array}{l}10 \cdot 9 \% \text { men and } \\
6.3 \% \text { women } \\
\text { had RDI }>5\end{array}$ & $\begin{array}{l}\text { Inductive plethysmography } \\
\text { to screen } 50 \% \text { of study } \\
\text { population }\end{array}$ & 14 \\
\hline
\end{tabular}

RDI-respiratory disturbance index (events/hour); study type B-questionnaire with full sleep studies in a subgroup of sleep apnoea positive replies; study type $\mathrm{C}$-overnight screening or sleep studies in entire group.

a random or selected subpopulation; finally, studies where all or most patients undergo full sleep studies or nocturnal respiratory monitoring. In the past five years studies of the latter two types (some ongoing) have shown that OSA is a common finding (table) but there is a wide range (1-9\%) in the reported prevalence of OSA. ${ }^{9-14}$ These differences may reflect disparity in methodologies, population differences in obesity and alcohol consumption, or even genetic variability. For example, the percentage of the population with heavy snoring doubles when the bed partner contributes to the questionnaire (fig 1). ${ }^{11}$ Some questionnaire data also do not seem to correlate highly with actual respiratory monitoring. The high prevalence in some studies does not correspond with a high frequency of such symptoms as hypersomnolence. For example, Jennum and Soul ${ }^{14}$ reported that $10.9 \%$ of men aged $30-60$ years had OSA (more than five apnoeas/hour) but only $1.9 \%$ complained of hypersomnolence. In our own epidemiological studies in Busselton, a Western Australian rural community, ${ }^{12} 10 \%$ of men aged $40-65$ years had more than 10 apnoeas per hour. This study used a well validated ambulatory monitoring system (the MESAM 4 recorder) ${ }^{15}$ which measures oxygen saturation, snoring, heart rate, and body position. It is important, however, to confirm whether this high prevalence is accompanied by a high prevalence of symptomatology and clinical consequences. It is clear that epidemiological information will need to be more sophisticated to allow a bet-

Figure 1 Increase in frequency of "often snoring" reported if wife is actually present at interview with subject. Adapted from reference 11 with permission.

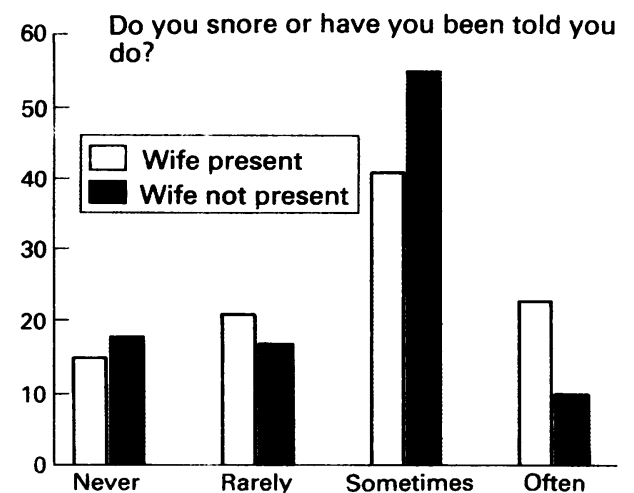

ter understanding of the relationship between sleep apnoea and clinical effects. Even a conservative view of the more recent OSA epidemiological studies, however, would suggest a potentially huge investigative and therapeutic load for health care systems.

\section{SYMPTOMS AND HISTORY TAKING: CAN CLINICAL ASSESSMENT PREDICT SLEEP APNOEA?}

If OSA is as common as epidemiological evidence suggests, it is important that simple methods of diagnosis are available. Obviously the simplest potential method of diagnosis would be by history and physical examination. The symptoms associated with OSA are many and varied and may include nocturnal choking attacks, morning headaches, gastrooesophageal reflux, nocturia, impotence, poor memory and concentration, and alteration in mood. ${ }^{16}$ However, those considered to be "key" or "major" symptoms are snoring, apnoeas witnessed by bed partners, and excessive daytime somnolence. ${ }^{16}$

The predictive power of these key symptoms has been examined in an Australian study. ${ }^{17}$ Apnoeas observed by a bed partner, with a lesser contribution from coexisting hypertension, body mass index, and age, produce a predictive model with high sensitivity but only moderate specificity. Other workers ${ }^{18}$ have found that these "key symptoms" explained only $36 \%$ of the variability in apnoea index. The authors suggested that the presence of key symptoms did not obviate the need for a properly performed diagnostic sleep study. Additional data provided by such measurements as neck circumference may help predict OSA, but not to the extent of replacing sleep studies. ${ }^{19}$

The nature of these symptoms also emphasises the importance of obtaining a history from the spouse, bed partner, and other family members in the proper assessment of the patient with OSA. Unless they are told few, if any, patients are aware that they snore or stop breathing during sleep, yet this concerns many bed partners to the point where they initiate the medical review. Excessive sleepiness may be recognised by the patient but often, for social or other reasons, this too may be denied by the sufferer of OSA-again 
underlining the critical importance of confirmatory history from a family member, friend, or workmate.

\section{INVESTIGATION OF OSA: DO WE NEED TO} MEASURE SLEEP?

Under ideal circumstances a full sleep study is the most appropriate investigation for assessing OSA. It allows accurate quantification of breathing events and provides information on sleep fragmentation and arousals which may be just as important in producing clinical effects as the respiratory events. However, such studies are expensive and, if current epidemiological surveys are accurate, full sleep studies for all suspected cases of OSA will be beyond the reach of health care systems. A recent EEC consensus report suggested that full sleep studies may not be appropriate for highly probable cases of OSA. ${ }^{20}$ A recent prospective study from Scotland ${ }^{21}$ compared the relative value of sleep and respiratory monitoring in the assessment of OSA. The authors concluded that sleep monitoring was not necessary in the assessment of patients suspected of having OSA and that respiratory measurements, particularly inductive plethysmography, were adequate. Oximetry alone was of limited value. Whether the findings of such a study could be extrapolated to home studies (where real cost savings would occur), interpreted by less experienced physicians, is not known. In contrast to the previous study, Gyulay et $a^{22}$ found that home oximetry was a sensitive screening test for OSA but specificity was low. There is now a plethora of devices available for sleep apnoea "screening" but their reliability and cost-benefit need to be proven, particularly for home use. If the desired end point is correct diagnosis of OSA and exclusion of other sleep disorders plus successful treatment of OSA in appropriate cases, how much is saved by screening studies? A key issue is the sophistication of the physician interpreting data; this has not been assessed in studies of sleep apnoea screening. ${ }^{20}$

\section{Predisposing factors}

A number of conditions or associations will predispose an individual to OSA. Only recent data in this area will be reviewed and the reader will be referred to more detailed reviews where appropriate.

\section{FAMILIAL}

Sleep apnoea aggregates in families. The risk of having OSA increases progressively with increasing numbers of affected relatives and this risk is independent of age, obesity, and alcohol consumption. ${ }^{23}$ Such risk may be the result of similarities in facial structure affecting upper airway dynamics in sleep.

\section{ALCOHOL}

Acute alcohol ingestion promotes the development of apnoea during later sleep. ${ }^{24}$ Some studies have suggested that lifetime alcohol consumption may be a risk factor for the development of OSA, ${ }^{2526}$ particularly if accompanied by respiratory failure. ${ }^{26}$ Other studies have failed to find a link between lifetime alcohol consumption and OSA. ${ }^{2728}$

\section{OBESITY}

Most patients with OSA are overweight, but 걱 the relationship between sleep apnoea and $\frac{}{2}$ weight is not a simple one. Studies employing $\stackrel{x}{x}$ different upper airway imaging modalities $\overrightarrow{\vec{F}}$ have shown that patients with sleep apnoea $\frac{0}{0}$ have a decreased pharyngeal cross sectional $\frac{0}{0}$ area, but the contributing role of upper air- $\overline{\bar{c}}$ way fat to this observation is controversial. ${ }^{29-31} \frac{\mathrm{T}}{\mathbb{D}}$ External neck circumference is increased in OSA and it has been stated that this measure- $\infty$ ment explains the link between obesity and $\vec{\circ}$ sleep apnoea. ${ }^{32}$ The hypothesis suggested by $\overrightarrow{\vec{\omega}}$ this study is that neck circumference is an index of neck fat deposition, and increased $\vec{x}$ fatty tissue in the neck region in turn promotes mass loading and obstruction of the upper airway in sleep, leading to sleep iे apnoea. However, in a study of 1464 patients presenting for sleep assessment we have 은 found waist measurement to be a better pre- $\overrightarrow{-}$ dictor of OSA than neck measurement. ${ }^{33}$ Nevertheless it is clear that OSA is associated with a central fat distribution. Abdominal $\vec{\theta}$ obesity may reduce lung volumes, particularly in the supine posture, and both may reflexly 8 influence upper airway dimensions and lead to impaired respiratory muscle force. ${ }^{34-36}$ The $\bar{D}$ link between central obesity and sleep apnoea $\stackrel{2}{2}$ may also be related to abnormal upper airway $\stackrel{\mathbb{2}}{2}$ muscle function. A reduction in type $I$ and $\overrightarrow{0}$ IIb muscle fibres in the middle pharyngeal 3 constrictor muscle has been found in nonobese habitual snorers. ${ }^{37}$ Similar changes in muscle fibre have been noted in other skeletal muscles in obesity. ${ }^{38}$ Moreover, studies of patients with OSA before and after weight loss have shown changes in upper airway function rather than structure, ${ }^{39}$ supporting a hypothesis of abnormal upper airway muscle function in obese patients with OSA. The 을 association of central obesity with increased cardiovascular risk indicates that this measure of adiposity should be controlled for in future studies of health risk in sleep apnoea and $\sigma$ arguably the reverse is also true.

\section{ENDOCRINE AND METABOLIC DISORDERS}

Several endocrine and metabolic disorders other than obesity are associated with an $\mathbb{D}$ increased prevalence of OSA. Hypothyroidism may lead to sleep apnoea by $\frac{T}{0}$ reducing chemosensitivity, ${ }^{40}$ myxoedematous $\stackrel{0}{\mathbb{D}}$ infiltration of the upper airway, and upper $\frac{\rho}{\mathbb{D}}$ airway myopathy. ${ }^{41}$ Interestingly, hypothyroid $\stackrel{\circ}{\square}$ rats have a similar upper airway muscle fibre structure as that reported in habitual snor- 8 ers. $^{42}$ It is controversial whether treatment with thyroxine will cure sleep apnoea inc. hypothyroidism. ${ }^{4143}$ Sleep apnoea may also provoke cardiovascular complications when initiating thyroid hormone replacement. ${ }^{41}$

Over $50 \%$ of patients with acromegaly have sleep apnoea and there is a higher than expected prevalence of central apnoea 
Figure 2 High rate of prevalence of sleep disordered breathing in a series of 53 patients with acromegaly. A higher than expected prevalence of central apnoea was observed.

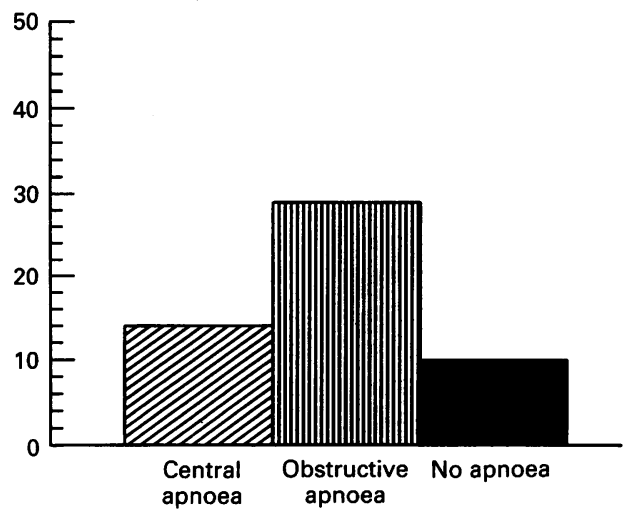

(fig 2). ${ }^{44}$ Increased biochemical activity (growth hormone and insulin-like growth factor 1 levels) are associated with the presence of central sleep apnoea. ${ }^{44}$ Treatment of acromegaly with the somatostatin analogue octreotide reduces the severity of sleep apnoea ${ }^{45}$; it is also associated with Cushing's disease. ${ }^{46}$

One important observation in OSA is the male predominance of the disorder. Interestingly, androgen treatment has been reported to provoke sleep apnoea ${ }^{478}$ and oestrogen treatment may reduce mild sleep apnoea in women. ${ }^{49}$ However, anti-androgen treatment does not appear to reduce the severity of OSA in men with severe sleep apnoea, ${ }^{50}$ and oestrogen therapy does not alter more severe forms of sleep apnoea in postmenopausal women. ${ }^{51}$

A recent report has identified a strong link between OSA and the connective tissue disorder, Marfan's syndrome. ${ }^{52}$ Nearly two thirds of patients with Marfan's syndrome have OSA and such patients, being tall and thin, do not have the typical body habitus of the sleep apnoea patient. The reason for the link between Marfan's syndrome and OSA is likely to be the abnormal compliance of the upper airway resulting from abnormal connective tissue. One important consideration is that the changes in intrathoracic pressure and blood pressure in OSA may provoke aortic dilatation and rupture, a common mode of death in Marfan's syndrome.

\section{Clinical sequelae}

ENDOCRINE AND METABOLIC EFFECTS

Patients with sleep apnoea are also characterised by a reversible neuroendocrine defect in growth hormone and testosterone secretion, probably due to central effects of sleep fragmentation and hypoxaemia.53 Growth hormone deficiency in OSA may explain impaired growth seen in children with upper airway obstruction which often improves following adenotonsillectomy. ${ }^{54}$ In adults impaired growth hormone secretion leads to central adiposity, reduced muscle and bone mass. ${ }^{55}$

\section{NEUROPSYCHOLOGICAI AND SOCIAI} CONSEQUENCES OF OSA

Excessive daytime sleepiness is characteristic but not pathognomonic of sleep apnoea. It is important to recognise that it may occur in a range of sleep disorders which may coexist with OSA. ${ }^{56}$ Sleepiness in OSA is predominantly related to repetitive arousal and sleep fragmentation, but a direct effect of hypoxaemia is possible. ${ }^{57}$ OSA is also characterised by a range of excessive daytime sleepiness from simply increased sleep time in a previously short sleeper to obtundation. Sleepiness may lead to both impairment of work performance ${ }^{58}$ and driving. ${ }^{59}$ One problem is that patients themselves may not be aware of their degree of sleepiness and information from family is often helpful. There is also a relatively poor correlation between severity of OSA and daytime sleepiness ${ }^{4}$ and no simple test will accurately quantify daytime sleepiness. Such a test would be useful to identify the high risk patients for treatment, assessing ability to work and drive and evaluating response to therapy. The standard test for quantifying sleepiness-the Multiple Sleep Latency Test (MSLT) - may not be useful in OSA and a modification-the Multiple Wakefulness Test (MWT)-has been shown to be more sensitive for detecting sleepiness before and after treatment for OSA. ${ }^{60}$

Patients with sleep apnoea perform worse on driving simulator tasks. ${ }^{6162}$ Haraldsson et al $^{61}$ reported that 15 patients with OSA ran off the road 101 times in a 60-90 minute simulated highway drive compared with only twice in 10 controls. Although poor performance in simulation tasks may be overcome by greater vigilance in the real life situation, data from a number of centres show a higher actual accident rate between patients with OSA and controls. ${ }^{5963}$ Interestingly, selfreported accident rates may not differ between patients with OSA and controls, questioning the reliability of patient history in this area. ${ }^{63}$ Loss of driving privileges can be economically and socially disastrous to patients and they may be reluctant to admit problems. ${ }^{63} 64$

Accidents where the driver falls asleep are likely to cause fatalities. ${ }^{64}{ }^{65}$ There are legal precedents both in US and British law where, if a patient drives a car with the knowledge that he or she frequently falls asleep while driving, such an action may be negligent and lead to either civil or criminal liability. One recent case occurred in the UK when a transport driver, with a history of sleepiness whilst driving, drove a semitrailer into a stationary queue of vehicles and killed six people. The driver was sentenced to three years imprisonment and was subsequently confirmed as having severe sleep apnoea ( $R$ Wilkinson, British Sleep Society Meeting, Leicester, 1992, unpublished). The responsibility of the physician dealing with sleepy patients who continue to drive will vary between countries. It is often frustrating to leave such patients untreated because of resource limitations in provision of appropriate treatment. This is especially the case as evidence exists that treatment with nasal continuous positive airway pressure (CPAP) dramatically improves daytime sleepiness ${ }^{56066}$ and even driving 
simulator performance. ${ }^{62}$

Several studies have found that patients with OSA perform poorly on psychometric tests compared with controls and a variable degree of improvement occurs after nasal CPAP therapy. ${ }^{67-70}$ Whether this is an effect of impaired concentration or actual deterioration in cognition and memory is uncertain. Follow up tests may produce practice effects that need to be controlled, as does education level and alcohol use. Few standard psychometric tests are designed to test for the subtle differences in cognition that are often reported by patients with OSA. Most studies have looked at small groups of patients with severe disease and it is unknown what cognitive impairment exists in milder forms of OSA.

\section{CARDIOVASCULAR SEQUELAE OF OSA}

The cardiovascular consequences of OSA can be considered from two aspects. Firstly, the acute cardiovascular changes that occur during an apnoea with the associated hypoxia, hypercapnia, acidosis, and arousal from sleep, and secondly, the chronic cardiovascular morbidity and mortality associated with OSA, namely hypertension, myocardial infarction, stroke, and death.

\section{Acute effects}

Obstructive apnoeas are accompanied by profound haemodynamic changes. ${ }^{71}$ Cyclical increases in systemic and pulmonary arterial blood pressure occur coincidently with obstructive events. ${ }^{72}$ Each apnoea can be considered in three phases with respect to the observed effects on blood pressure, heart rate, sympathetic and parasympathetic nerve activity, and cardiac output. ${ }^{71}$ Phase 1 (recovery from the previous apnoea typically during the early part of the next apnoea) is characterised by minor pleural pressure swings, minimal changes in heart rate and muscle sympathetic nerve activity (MSNA), and modest changes in oxygen saturation. As the apnoea progresses (phase 2) there is progressive hypoxaemia, increasing pleural pressure swings, bradycardia (and possibly bradyarrhythmias), heightened MSNA, and an overall rise in blood pressure. With arousal and resumption of ventilation (phase 3) oxygen saturation returns to normal. There are significant increases in heart rate and blood pressure may rise to levels ranging from 200 to 300 $\mathrm{mm} \mathrm{Hg}$. In phase 3 MSNA increases, but this appears to be rapidly interrupted before the peak in blood pressure following apnoea. There is a fall in stroke volume during apnoea, particularly at its termination..$^{73}$ The combination of fall in stroke volume and rise in blood pressure suggests a substantial increase in total peripheral resistance.

The potentiation of MSNA activity during apnoea is likely to be the result of a combination of apnoea and hypoxaemia. Somers and coworkers were able to demonstrate a 12 fold increase in the MSNA response to hypoxia by voluntary apnoea in normal subjects. ${ }^{75}$ However, the relative contribution of hyp- oxaemia is controversial, particularly regarding the blood pressure rise in phase 3 . It has been suggested that arousal is the primary stimulus for this rise in blood pressure. ${ }^{76}$ Others have provided evidence supporting a contributory role for hypoxaemia. ${ }^{7778}$ Whatever the mechanism, the considerable changes in cardiorespiratory behaviour, together with reported changes in cerebral blood flow, provide an environment for increasing the risk of various vascular disease end points.

\section{Chronic effects}

It is unknown to what degree these acute cardiovascular changes produce chronic effects. A number of groups have reported $\vec{\circ}$ that patients with OSA are characterised by markedly elevated sympathetic nerve traffic while awake which may promote chronic elevation of blood pressure. ${ }^{78-80}$ In addition we have recently observed that patients with OSA have a potent pressor response to eucapnic hypoxia compared with controls (fig of 3). ${ }^{81}$ This pressor response was related to dis- 응 ease severity and likely to be the result of exposure of the cardiovascular system to $\subseteq$ intermittent hypoxia in sleep. In normal subjects the central effects of hypoxaemia tend to increase blood pressure but these effects are counterbalanced by peripheral vasodilation. ${ }^{81}$ The pressor response in OSA may be due to impaired vasodilatory mechanisms, as there is preliminary evidence of an attenuated forearm blood flow response to acetylcholine in $\stackrel{\mathbb{Q}}{2}$ patients with OSA (J Carlson, J Hedner, per- $\overrightarrow{0}$ sonal communication). This in turn indicates $\exists$ impaired endothelial dependent (nitric oxide mediated) vasodilation. Interestingly, the vasodilatory response to hypoxia in chemodenervated rats is mediated by nitric oxide. ${ }^{82}$

Apart from nitric oxide, other vasoactive $\times$ mediators appear to be altered in OSA. These 3 include eicosanoids, ${ }^{83}$ endothelin, ${ }^{84}$ and adenosine ${ }^{85}$ Intrathoracic pressure swings in $\frac{3}{3}$ OSA may alter volume regulating hor- 0 mones, ${ }^{8687}$ although some of these changes may potentially attenuate rises in blood pres-

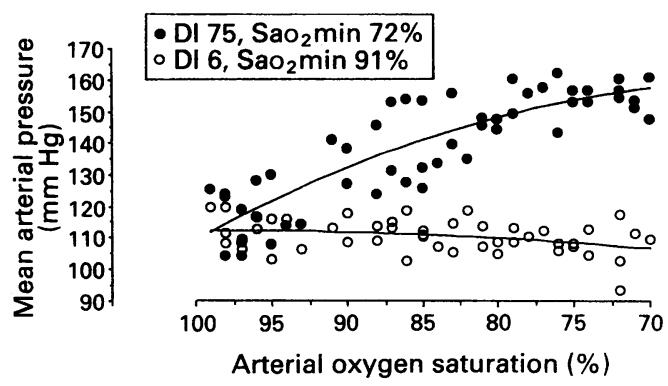

Figure 3 Mean aterial pressure at different oxygen saturation levels during a hypoxic ramp test in two patients with different severity of sleep apnoea. Patient 1 (closed circles) had severe sleep apnoea (respiratory disturbance index (DI) 75 events per hour, minimum oxygen saturation in sleep ( $\mathrm{SaO}_{2} \mathrm{~min}$ ) $72 \%$ ) and patient 2 (open circles) had minimal obstructive sleep apnoea (DI 6 events per hour and $\mathrm{SaO}_{2} \mathrm{~min}$ 91\%). Values from two tests in each patient are shown and the fitted polynomial regression lines. Adapted from reference 81 with permission. 
sure. In addition, changes in intracranial pressure may influence blood pressure. ${ }^{88}$ Other evidence for a potential effect of OSA on development of hypertension has been provided by an elegant series of studies in rats exposed to seven weeks of intermittent hypoxia. ${ }^{89-91}$ These animals developed persistent elevation of daytime mean arterial pressure. Sectioning of the carotid sinus nerve and chemical peripheral sympathectomy with 6-hydroxydopamine eliminated the persistent elevation of blood pressure. ${ }^{9091}$

Increased left ventricular wall thickening, independent of resting daytime blood pressure, has been observed in OSA. ${ }^{92}$ This may result from acute increases in left ventricular afterload leading to left ventricular wall stress and increased sympathetic tone, causing a direct trophic effect on the myocardium. ${ }^{92}$ Interestingly, both left and right ventricular hypertrophy have been found after repetitive hypoxia in the rat. ${ }^{89}$ Left ventricular hypertrophy has an adverse prognosis in itself and may also lead to impaired myocardial contractility, perhaps exacerbated by an adverse effect of tissue hypoxia on myocardial muscle metabolic demand. ${ }^{71}$ Recently, Malone and coworkers reported that nasal CPAP improved left ventricular function in men with OSA and idiopathic dilated cardiomyopathy. ${ }^{94}$ Withdrawal of CPAP led to deterioration in myocardial function. Left ventricular hypertrophy also occurs more frequently in patients who do not have the normal nocturnal "dip" in measurements of ambulatory 24 hour blood pressure. ${ }^{95}$ Patients with OSA certainly have episodic rises in blood pressure at night, but the overall pattern of 24 hour ambulatory blood pressure shows a preserved diurnal pattern. ${ }^{96}$

Despite a number of potential mechanisms for the development of sustained hypertension, there is no irrefutable evidence that OSA directly causes daytime hypertension..$^{71} 97$ Sleep apnoea is a common finding in patients attending hypertension clinics, ${ }^{719798}$ but this may be due to shared confounding factors such as central obesity ${ }^{33}$ and increasing age. Large scale epidemiological studies often find

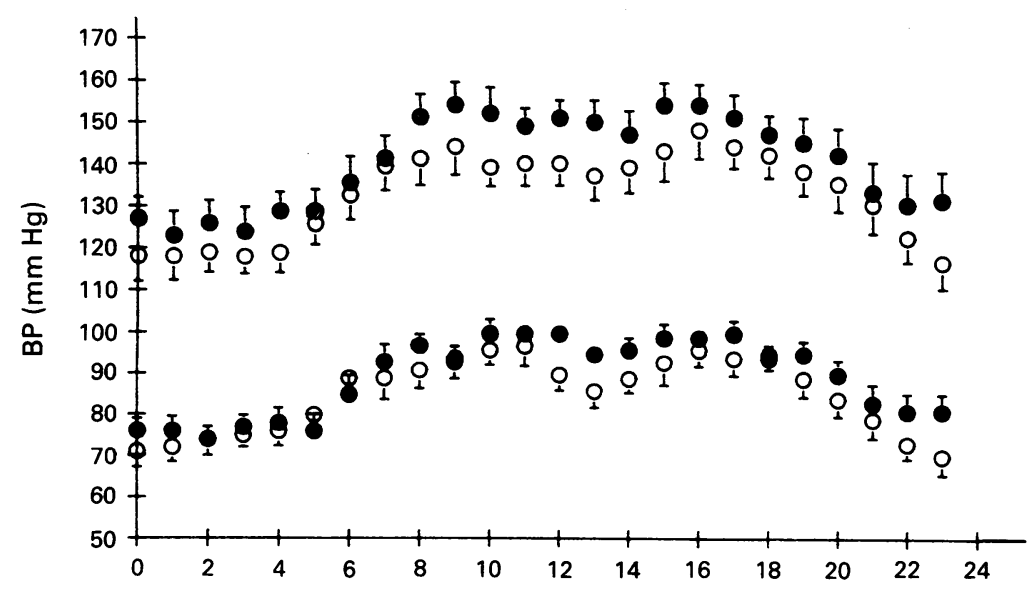

Figure 4 Fall in systolic and diastolic ambulatory blood pressure before (closed circles) and after (open circles) eight weeks of nasal CPAP in 14 men not using antihypertensive agents. Adapted from reference 107 with permission. an association between snoring (reported on questionnaire) and hypertension, but these studies are typically also confounded by coexisting obesity or interpretation is difficult because there are only a few cases of OSA or hypertension. ${ }^{71}$ In a recent study of an Oxfordshire general practice, for example, the number of overnight oxyhaemoglobin desaturations was correlated with arm cuff pressure, but this was not independent of age or body mass index on multivariable analysis. ${ }^{28}$ However, only $5 \%$ of the subjects were obese and the actual numbers of individuals with hypertension was not reported. In another study, examining the relationship between blood pressure and OSA in a sleep clinic population, patients with known hypertension or on antihypertensive agents were excluded. ${ }^{99}$ Despite these methodological limitations, such studies indicate that the independent association between classic measures of OSA severity, such as apnoea index or minimum oxygen saturation in sleep, and hypertension is unlikely to be strong. We observed recently that morning but not evening blood pressure was related to severity of OSA, independent of central obesity and age. Nevertheless, these three variables only explained $18 \%$ of the variance in blood pressure, with the largest contribution from central obesity. ${ }^{33}$ Future studies correlating blood pressure with other measures, such as arousal index or even the magnitude of the blood pressure response to individual apnoeas, may prove an important line of investigation.

Prospective studies examining the longitudinal development of hypertension in untreated patients with OSA compared with matched controls are unlikely to be performed due to the ethical issues of not treating sleep apnoea. One potential method of avoiding the problems of confounding variables and interpretation of cross sectional statistical data is effectively to treat OSA and examine the subsequent response of blood pressure. Factors such as weight loss and alcohol consumption need to be controlled. Patients should be withdrawn from antihypertensive medication ideally, but this may not be possible, particularly in patients with OSA. ${ }^{100}$ Since Coccagna and colleagues reported that blood pressure fell in five patients with OSA after tracheostomy, ${ }^{101} \mathrm{sev}$ eral studies have looked at the blood pressure response to treatment of sleep apnoea..$^{98102103}$ Most of these studies are limited by small numbers, confounded by parallel weight change and antihypertensive medications or use of single cuff measurements as an index of blood pressure. More recently two groups have reported decreased nocturnal and morning awake intra-arterial blood pressure following CPAP therapy. ${ }^{104} 105$ Naughton and Pierce reported a fall in automated daytime blood pressure readings in hypertensive patients with OSA after one week of CPAP. ${ }^{106}$ However, some of these patients were also receiving antihypertensive drugs. In a study of 24 hour ambulatory blood pressure in 19 men with OSA before and after eight weeks 
of nasal CPAP ${ }^{107}$ there was a moderate fall in 24 hour mean systolic and diastolic blood pressure during the day but only in the systolic blood pressure at night (fig 4). This fall occurred in the 14 patients with good CPAP compliance but not in those unable to use CPAP. This is the first study to report a decrease in ambulatory daytime blood pressure following treatment of OSA. Such a daytime fall may not be unexpected in view of the high sympathetic nerve traffic during wakefulness observed in untreated patients with $\mathrm{OSA}^{78-80}$ and the decrease in sympathetic activity seen following nasal CPAP treatment. ${ }^{71}$ Recent preliminary data have also suggested that patients with OSA may have abnormally high responses to daytime stressors such as mental arithmetic which are reversible with treatment (JH Peter, personal communication). One criticism of this 24 hour ambulatory blood pressure study is the lack of a placebo treated control group to avoid "regression to the mean." This phenomenon has not, however, been observed in 24 hour ambulatory blood pressure studies ${ }^{108}$ and "placebo" CPAP has not been successfully used in any short or long term study. Such a technique would be obvious to the patient and bed partner as snoring and upper airway obstruction would continue and the expected improvement in daytime sleepiness with CPAP treatment would not occur.

\section{OSA, STROKE, MYOCARDIAL INFARCTION AND} DEATH

The advent of nasal CPAP has prevented large studies investigating the natural history of untreated OSA. However, in certain sleep disorder centres established in the 1970s long term data are available which strongly suggest that the mortality risk is increased in untreated sleep apnoea. ${ }^{109-112} \mathrm{He}$ et al ${ }^{109}$ observed an increased cumulative mortality in untreated patients with an apnoea index above 20 compared with those having an index below 20. Tracheostomy or CPAP treatment, but not uvulopalatopharyngoplasty (UPPP), reduced the mortality risk. These authors, however, did not provide information on the cause of death, but studies from Stanford ${ }^{110}$ and Haifa ${ }^{112}$ suggest an excess of cardiovascular deaths in OSA. A number of groups have reported an increased risk of myocardial infarction ${ }^{11314}$ and stroke ${ }^{115}$ in sleep apnoea. Snoring is a strong risk factor for sleep related strokes while sleep apnoea symptoms (snoring plus reported apnoeas or excessive daytime sleepiness) increase the risk of cerebral infarction with an odds ratio of 8.0.115 Cerebral blood flow changes associated with sleep apnoea may certainly be linked to these observations. ${ }^{116}$ However, there is no information currently available on an increased thrombotic tendency or accelerated atherosclerosis in sleep apnoea.

OSA, RESPIRATORY FAILURE AND PULMONARY HYPERTENSION

The "Pickwickian" patients described in older literature were often characterised by marked obesity, right heart failure, and awake respiratory failure with hypercapnia. ${ }^{117}$ They clearly represent the severe end of the spectrum of OSA, and it is evident that upper airway obstruction during sleep in the presence of other factors will produce the "Pickwickian" patient. What are the factors that will transform a patient with OSA into a "Pickwickian" patient? Firstly, there is likely 음 to be a complex interrelationship between these factors. Some patients develop hypercapnia without evidence of right heart failure $\stackrel{\vec{D}}{+}$ and the reverse is also true. Most studies examining this interrelationship are limited in $\frac{\overline{5}}{\overline{5}}$ size and vary in the method of assessing right $\frac{\bar{D}}{\vec{D}}$ heart failure. The key factors suggested are $\unrhd$

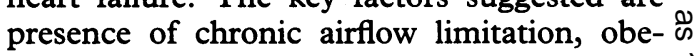
sity, awake hypoxaemia, hypercapnia, pro- $\overrightarrow{0}$ found nocturnal hypoxaemia, and alcohol $\vec{A}$ consumption. ${ }^{118-122} \mathrm{~A}$ recent preliminary report has shown that daytime $\mathrm{PCO}_{2}$ and $\overrightarrow{\vec{x}}$ $\mathrm{FEV}_{1}$ explain $29 \%$ of the variability in pulmonary artery pressure in sleep apnoea. Daytime hypoxaemia had no independent - Vे contribution. Of 78 patients with pulmonary hypertension and $\mathrm{FEV}_{1}>1.51,30 \%$ had a $\mathrm{PO}_{2}>80 \mathrm{~mm} \mathrm{Hg}$. These data suggest that patients with OSA can often develop pul- $\subseteq$ monary hypertension in the absence of daytime hypoxaemia. ${ }^{121}$ Treatment of $\vec{\theta}$ "Pickwickian" patients and other patients with OSA and pulmonary hypertension leads to a normalisation of both hypercapnia and pulmonary artery pressure. ${ }^{120122}$

\section{Treatment}

Despite many drug trials and attempts at $\frac{0}{3}$ electrical stimulation of the upper airway, ${ }^{123} \vec{\partial}$ the most accepted treatments for OSA are nasal CPAP and surgery.

\section{CPAP}

The advent of nasal CPAP revolutionised $\frac{0}{3}$ positive airway pressure ventilation and allowed a wider range of patients to be $\frac{0}{3}$ treated. Nasal CPAP is an effective treatment but compliance is variable. ${ }^{124}$ When accurate hours of use are measured, patient compli- $\frac{D}{0}$ ance is $70 \% .^{125}$ The improvements in mask and machine technology are likely to further $\mathcal{N}$ increase compliance as will humidification $N$ devices aimed at reducing nasal side effects. N It is not known whether the variation of inspiratory and expiratory pressure ${ }^{126}$ with the use of the more expensive bi-level positive airway pressure devices will influence patient com-? pliance. Indeed, some authors have suggested 0 that reduction of expiratory positive airway $\frac{\vec{D}}{\mathbb{D}}$

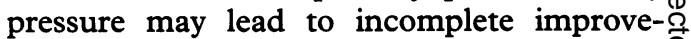
ment in upper airway calibre. ${ }^{127}$ Although the $\mathbb{Q}$ severity of OSA may influence compliance, patient symptoms and their response to CPAP provide a powerful reinforcement to machine use.

Patients with OSA and daytime respiratory? failure may benefit from nasal intermittent positive pressure ventilation (nIPPV). Such patients may require high CPAP pressures and, in the short term, may prefer nasal ventilation. ${ }^{28}$ These treatment periods of nasal ventilation may be brief and, after improve- 
ment in blood gas levels, nasal CPAP can be commenced.

\section{SURGERY}

\section{Tracheostomy}

Before the introduction of nasal CPAP as a treatment for OSA tracheostomy was the main method of treatment. The current indication for tracheostomy is in patients with severe OSA who have been unable to comply with CPAP. Our clinical practice is to fully evaluate such patients as hospital admissions with repeat polysomnography, intensive support for nasal CPAP treatment including ENT review, humidification of inspired air through the CPAP machine and, if necessary, customised CPAP masks. Tracheostomy can produce significant morbidity and may be a problem in the morbidly obese, fat necked individual. However, skilful minimalist surgery and regular nursing care allow tracheostomy to be a therapeutic option in some patients.

\section{Facial reconstructive surgery}

Many patients with OSA have abnormalities in facial structure on cephalometry ${ }^{129}$ and it has been suggested that correction of such factors by maxillofacial surgery will lead to cure in sleep apnoea. ${ }^{130}$ However, the correlation of mechanical characteristics of the pharyngeal airway with cephalometry is only indirect and, moreover, such surgery is expensive, requiring several operative procedures. Virtually all cases have been reported by one group ${ }^{130}$ and therefore efficacy will need to be shown in wider clinical trials using the expertise of several surgeons.

\section{Uvulopalatopharyngoplasty (UPPP)}

This operation was developed by Ikematsu for the treatment of heavy snoring in the early 1950 s. ${ }^{131}$ A similar operation was used by veterinary surgeons to treat bothersome breathing in bulldogs, a breed of dog potentially useful as a large animal model of OSA. ${ }^{132}$ The introduction of UPPP for the treatment of OSA into North America occurred in $1981,{ }^{133}$ the same year as the efficacy of nasal CPAP in OSA was first reported. ${ }^{134}$ Initially there was great enthusiasm for performing UPPP, often with minimal patient assessment. The accumulated data from many studies over the past decade, however, suggest extreme caution in performing this form of surgery for OSA. ${ }^{135-138}$ There is still no consensus on the most appropriate methods to assess the likely success of UPPP in an individual patient. ${ }^{139-140}$ Awake tests such as computed tomographic scanning, nasopharyngoscopy, and even multilevel upper airway pressure measurement in sleep have been used. ${ }^{139} 140$ Often areas that narrow on preoperative assessment are still narrowed postoperatively, or new areas of upper airway narrowing are found. ${ }^{135-139}$ Moreover, the response to surgery is highly variable. Most papers define a "cure" as a $50 \%$ reduction in the number of apnoeas per hour of sleep; in many patients with repetitive apnoea, however, these "cures" will still leave a substantial degree of sleep disordered breathing. Results are frequently reported without detailed examination of sleep quality, hypopnoea, or arousals. Polo et al, ${ }^{141}$ while observing a decrease in obstructive apnoea following UPPP, found an increase in partial upper airway obstruction thus stressing the importance of close postoperative follow up. This may also explain why investigators reporting apnoea reduction following UPPP find no correlation between subjective and objective improvement. ${ }^{135}$

One of the problems in examining the long term efficacy of UPPP is that most papers report short term results or have incomplete follow up. Recently Larsson $e t$ al ${ }^{136}$ reported a two year follow up of 50 consecutive patients who underwent UPPP. After six weeks $60 \%$ of patients were classified as "responders" (50\% decrease in apnoea index or number of apnoeas per hour). At two years the "response rate" had fallen to $36 \%$. In addition there are data ${ }^{135}$ 137-138 $^{13}$ suggesting an appreciable morbidity and mortality for patients treated by UPPP, while the increased mortality of OSA is not modified by UPPP. ${ }^{109}$ There is also some evidence that the vibration of snoring may protect against further upper airway obstruction, ${ }^{142}$ suggesting that removal of the vibrating tissues (plate, uvula) may critically alter important upper airway afferent receptors, thereby causing narrowing and airway closure during sleep at other sites postoperatively.

Recently a novel technique using nasopharyngoscopy during sleep, simultaneous use of nasal CPAP to manipulate intrapharyngeal pressure, and digitised computer assessment of airway lumen size has been employed to select patients who may respond to UPPP. ${ }^{140}$ The authors could identify patients with exclusively nasopharyngeal narrowing of the passive airway. Such patients had $50 \%$ improvement in severity of sleep apnoea four months after UPPP compared with no change in the non-exclusively nasopharyngeal occluders. There was, however, a deterioration in the severity of OSA at 14 month follow up. Moreover, "responders" still had a substantial degree of disordered breathing in sleep at 14 months after surgery (mean apnoea index 58, with $35 \%$ of total sleep time spent in disordered breathing). Such pre-UPPP assessment techniques are complex and expensive and current results do not seem to warrant more widespread use. It is possible that better results may be produced in patients with milder OSA. It is therefore important to stress that UPPP remains an experimental treatment method in OSA. Careful objective preoperative and postoperative assessment of breathing during sleep with long term follow up should be performed.

\section{Conclusion}

Obstructive sleep apnoea is a common disorder which will become an increasingly important part of respiratory practice. The 
best methods of diagnosis are costly and increased sophistication of screening devices and interpreting physicians are required to reduce the need for full polysomnography. There is a wide range of clinical disorders associated with OSA which affect the decision to treat patients. However, in some cases the link between OSA and these clinical disorders has not been proved convincingly. Studies clarifying these issues will allow better selection of patients requiring treatment. Nasal CPAP is the standard treatment for OSA and tracheostomy should only be considered in patients truly unable to tolerate CPAP. Uvulatopalatopharyngoplasty and facial reconstructive surgery should only be considered as part of objective controlled trials.

Dr McNamara is a recipient of a National Health and Medical Research Council of Australia postgraduate scholarship and Dr Grunstein is a recipient of a National Heart Foundation of Australia overseas travelling fellowship.

1 Saunders NA, Sullivan CE (eds). Sleep and breathing. New York: Marcel Dekker, 1993.

2 Guilleminault C, Tilkian A, Dement W. The sleep apnea syndromes. Annu Rev Med 1976;27:465-84.

3 Guilleminault C, Partinen M. Obstructive sleep apnea syndrome. Clinical research and treatment. New York: Raven Press, 1990.

4 Guilleminault C, Stoohs R, Clerk A, Simmons J, Labanowski $M$. From obstructive sleep apnea syndrome to upper airway resistance syndrome: consistency of daytime sleepiness. Sleep 1992;15(Suppl):S13-6.

5 Gould GA, Whyte KF, Rhind GB, Airlie MA, Catteral JR, Shapiro CM, et al. The sleep hypopnea syndrome. Am Rev Respir Dis 1988;137:895-8.

6 Ambrogetti A, Olsen LG, Saunders NA. Differences in the symptoms of men and women with obstructive sleep apnea. Aust NZ F Med 1991;21:863-6.

7 Rosen CL, D'Andrea L, Haddad GG. Adult criteria for obstructive sleep apnea do not identify children with serious obstruction. Am Rev Respir Dis 1992;146:1231-4.

8 Guilleminault C, Tilkian A, Lehrman K, Forno L Dement WC. Sleep apnea syndrome: states of sleep and autonomic dysfunction. I Neurol Neurosurg Psychiatry 1977;40:718-24.

9 Gislason T, Ahlmqvist M, Ariksson G, Taube A, Boman G. Prevalence of sleep apnea syndrome amongst Swedish men. $\mathcal{F}$ Clin Epidemiol 1988;41:571-6.

10 Cirignotta F, d'Alessandro R, Partinen M, Zucconi $M$, Cristina E, Gerardi R, et al. Prevalence of every night snoring and obstructive sleep apneas among 30-69 year old men in Bologna, Italy. Acta Neurol Scand 1989; 79:366-72.

11 Stradling JR, Crosby JH. Predictors and prevalence of obstructive sleep apnoea and snoring in 1001 middle aged men. Thorax 1991;46:85-90.

12 Bearpark H, Elliott L, Cullen S, Grunstein R, Schneide $\mathrm{H}$, Althaus $\mathbb{W}$, et al. Home monitoring demonstrates high prevalence of sleep disordered breathing in men in the Busselton population. Sleep Res 1991;20A:411.

13 Young T, Zaccaro D, Leder R, et al. Prevalence and correlates of sleep disordered breathing in the Wisconsin sleep cohort study. Am Rev Respir Dis 1991:143:A380.

14 Jennum P, Soul A. Epidemiology of snoring and obstructive sleep apnoea in a Danish population age 30-60. f Sleep Res 1992;1:240-4.

15 Stoohs R, Guilleminault C. MESAM 4: an ambulatory device for the detection of patients at risk for obstructive sleep apnea syndrome (OSAS). Chest 1992;101:1221-7.

16 Sullivan CE, Issa FG. Obstructive sleep apnea. Clin Chest Med 1985;6:632-4.

17 Crocker BD, Olson LG, Saunders NA, Hensley MJ, Mckeon JL, Muree Allen $\mathrm{K}$, et al Estimation of the probability of disturbed breathing during sleep before a sleep study. Am Rev Respir Dis 1990;142:14-8.

18 Hoffstein V, Szalai J. Predictive value of clinical features in diagnosing obstructive sleep apnea. Sleep 1993;16: $118-22$.

19 Davies RJO, Ali NJ, Stradling JR. Neck circumference and other clinical features in the diagnosis of obstructive sleep apnoea syndrome. Thorax 1992;47:101-5.

20 Stradling J. Consensus report: sleep studies for sleeprelated breathing disorders. F Sleep Res 1992;1:265-73.

21 Douglas NJ, Thomas S, Jan MA. Clinical value of polysomnography. Lancet 1992;339:347-50.

22 Gyulay SG, Olson LG, Hensley MJ, King MT, Muree
Allen $\mathrm{K}$, Saunders NA. A comparison of clinical assessment and home oximetry in the diagnosis of obstructive sleep apnea. Am Rev Respir Dis 1993;147:50-3.

23 Redline S, Tosteson T, Tishler PV, Carskadon MA Millman RP. Studies in the genetics of obstructive sleep apnea: familial aggregation of symptoms associated with sleep related breathing disturbances. Am Rev Respir Dis 1992;145:440-4.

24 Issa FG, Sullivan CE. Alcohol, snoring and sleep apnea f Neurol Neurosurg Psychiatry 1982;45:353-9.

25 Tan ETH, Lambie DG, Johnson RH, Robinson BJ, Whiteside EA. Sleep apnoea in alcoholic patients after withdrawal. Clin Sci 1985,69:655-61.

26 Chan CS, Grunstein RR, Bye PTB, Woolcock AJ, Sullivan CE. Obstructive sleep apnea with severe $\mathcal{G}$ chronic airflow limitation-comparison of hypercapnic and eucapnic patients. Am Rev Respir Dis 1989;140: 1274-8.

27 Jalleh R, Fitzpatrick MF, Mathur R, Douglas NJ. Do patients with the sleep apnea/hypopnea syndrome drink more alcohol? Sleep 1992;15:319-21.

28 Stradling JR, Crosby JH. Relation between systemic hypertension and sleep hypoxemia or snoring: analysis in 748 men drawn from a general practice. $B M F 1990$; 300:75-8

29 Horner RL, Mohiaddin RH, Lowell DG, Shea SA, Burman ED, Longmore DB, et al. Sites and sizes of fat deposits around the pharynx in obese patients with obstructive sleep apnea and weight matched controls. Eur Respir ₹ 1989;2:613-22.

30 Eller K, Woodson H, Gay SB, Suratt PM. Pharyngeal fat in obstructive sleep apnea. Am Rev Respir Dis 1992; . 145:214.

31 Schwab RJ, Prasad A, Gupta KB, Pack AI, Listerud J, O Hoffman EA, et al. Fat and water measurements of 을 upper airway soft tissues in normal subjects and patients with sleep disordered breathing using magnetic resonance proton spectroscopy. Am Rev Respir Dis 1992; 145:214.

32 Davies RJO, Stradling JR. The relationship between neck circumference, radiographic pharyngeal anatomy, and obstructive sleep apnea. Eur Respir f 1990;3:509-14.

33 Grunstein RR, Wilcox I, Yang TS, Gould Y, Hedner JA. Snoring and sleep apnea in men-association with central obesity and hypertension. Int $\mathcal{F}$ Obesity (in press)

34 Begle RL, Badr S, Skatrud JB, Dempsey JA. Effect of lung inflation on pulmonary resistance during NREM sleep. Am Rev Respir Dis 1990;141:854-60.

35 Hoffstein V, Zamel N, Phillipson EA. Lung volume dependence of pharyngeal cross-sectional area in patients with obstructive sleep apnea. Am Rev Respir Dis patients with obs

36 Lopata M, Onal E. Mass loading, sleep apnea, and the pathogenesis of obesity hypoventilation. Am Rev Respir Dis 1982;126:640-5.

37 Smirne S, Iannaccone S, Ferini-Strambi L, Comola $M$ Colombo E, Nemni R. Muscle fibre type and habitual snoring. Lancet 1991;337:597-9.

38 Wade AJ, Marbut MM, Round JM. Muscle fibre type and the aetiology of obesity. Lancet 1990;335:805-8.

39 Rubinstein I, Colaptino N, Rotstein LE, Brown IG, Hoffstein V. Improvement in upper airway function after weight loss in patients with obstructive sleep apnea. Am Rev Respir Dis 1988;138:1192-5.

40 Zwillich CW, Pierson DJ, Hofeldt FD, Lufkin EG, Weil JV. Ventilatory control in myxedema and hypothyroidism. N Engl f Med 1975;292:662-5.

41 Grunstein RR, Sullivan CE. Hypothyroidism and sleep 을 apnea. mechanisms and management. $\mathrm{Am} \mathcal{F} \mathrm{Med} 1988$; 85:775-9.

42 Petroff BJ, Kelly AM, Rubinstein NA, Pack AI. Effect of hypothyroidism on myosin heavy chain expression in rat pharyngeal dilator muscles. $\mathcal{F}$ Appl Physiol 1992;73: N 179-87.

43 Rajagopal KR, Abbrecht PH, Derderian SS, Pickett C, Hofeldt F, Tellis CJ, et al. Obstructive sleep apnea in 0 hypothyroidism. Ann Intern Med 1984;101:471-4.

44 Grunstein RR, Ho KY, Sullivan CE. Sleep apnea and $\stackrel{\$}{+}$ acromegaly. Ann Intern Med 1991;115:527-32.

45 Grunstein RR, Stewart DA, Handelsman DJ, Ho KY, T Sullivan CE. Growth hormone and sex steroids in sleep 0 apnoea. In: Horne J, ed. Sleep 90. Bochum: Pontenagel $\mathbb{D}$ Press, 1990:422-5.

46 Shipley JE, Starkman MN. EEG sleep in Cushing's dis- \ֶ ease. Sleep Res 1990;19:102.

47 Schneider BK, Pickett CK, Zwillich CW, Weil JV, McDermott MT, Santen RJ, et al. Influence of testosterone on breathing during sleep. F Appl Physiol 1986; 61:618-23.

48 Johnson MW, Arch AM, Remmers JE. Induction of the obstructive sleep apnea syndrome in a woman by exoge- $?$ nous androgen administration. Am Rev Respir Dis 1984. 129:1023.

49 Pickett CK, Regensteiner JG, Woodard WD, Hagerman DG, Weil JV, Moore LG. Progestigin and estrogen reduce sleep-disordered breathing in post-menopausal women. 7 Appl Physiol 1989;66:1656-61.

50 Stewart D, Grunstein RR, Berthon-Jones M, Handelsman 
DJ, Sullivan CE. Androgen blockade does not affect sleep disordered breathing or chemosensitivity in men with obstructive sleep apnea. Am Rev Respir Dis 1992; 146:1389-93.

51 Cistulli P, Barnes D, Grunstein R, Sullivan CE. Effect of short-term hormone replacement in post menopausal women with obstructive sleep apnoea. Am Rev Respir Dis 1993;147:A686

52 Cistulli P, Sullivan CE. Sleep apnea in Marfan's syndrome. Am Rev Respir Dis 1993;147:645-8.

53 Grunstein RR, Handelsman DJ, Lawrence SJ, Blackwell C, Caterson ID, Sullivan CE. Neuroendocrine dysfunction in sleep apnea. Reversal by continuous nasal positive airway pressure. F Clin Endocrinol Metab 1989; 68:352-8.

54 Stradling JR, Thomas G, Williams P, Warley AH, Freeland A. Effect of adenotonsillectomy on nocturnal hypoxemia, sleep disturbance and symptoms in snoring children. Lancet 1990;335:249-53.

55 Rudman D, Feller AG, Nagraj HS, Gergans GA, Lalitha PY, Goldberg AF, et al. Effects of human growth hormone in men over 60 years old. $N$ Engl $f \mathrm{Med}$ 1990;323:1-6.

56 Roth T, Roehrs T, Carskadon M, Dement W. Daytime sleepiness and alertness. In: Kryger MA, Roth $T$, Dement WC, eds. Principles and practice of sleep medicine. Philadelphia: Saunders, 1989:14-23.

57 Bedard MA, Montplaisir J, Richer F, Malo J. Nocturnal hypoxemia as determinant of vigilance impairment in sleep apnea syndrome. Chest 1991;100:367-70.

58 Kales A, Caldwell AB, Cadieux RJ, Vela-Bueno A, Ruch LG, Mayes SD, et al. Severe obstructive sleep apnea-II: associated psychological and psychosocial consequences. $f$ Chron Dis 1985;38:426-37.

59 Findley L, Unverzagt M, Suratt P. Automobile accidents in patients with obstructive sleep apnoea. Am Rev Respir Dis 1988;138:337-40.

60 Poceta JS, Timms RM, Jeong D-U, Ho S-L, Erman MK, Mitler MM. Muliple wakefulness test in obstructive sleep apnea syndrome. Chest 1992;101:893-7.

61 Haraldsson P, Carenfelt C, Laurell H, Tornross J. Driving vigilance simulator test. Acta Otolaryngol (Stockh) 1990;110:136-40.

62 Findley L, Fabrizio M, Knight H, Norcross BB, La Forte AJ, Suratt PM. Driving simulator performance in patients with sleep apnea. Am Rev Respir Dis 1989; 140:529-30.

63 Bearpark H, Fell D, Grunstein RR, Leeder S, BerthonJones $M$, Sullivan CE. Snoring and sleep apnea have adverse effects on driving: implications for road safety. Med $\mathcal{f}$ Aust (in press).

64 Findley L, Weiss J, Jabour E. Serious automobile crashes caused by undetected sleep apnea. Arch Intern Med 1991;151:1451-2.

65 Parsons M. Fits and other causes of loss of consciousness whilst driving. $Q \mathcal{F}$ Med 1986;227:295-303.

66 Rajogobal KR, Bennett LL, Dillard TA, Tellis CJ, Tenholder MF. Overnight nasal CPAP improves hypersomnolence in sleep apnea. Chest 1986;90:172-6.

67 Greenberg GD, Watson RK, Deptula D. Neuropsychological dysfunction in sleep apnea. Sleep 1987; 10:254-62.

68 Bearpark H, Grunstein R, Touyz S, Channon L, Sullivan CE. Cognitive and psychological dysfunction in sleep apnea before and after treatment with CPAP. Sleep Res 1987;17:303.

69 Cheshire K, Engelman H, Deary I, Shapiro C, Douglas NJ. Factors impairing daytime performance in patients with sleep apnea/hypopnea syndrome. Arch Intern Med 1992;152:538-41.

70 Montplaisir J, Bedard MA, Richer F, Rouleau I. Neurobehavioural manifestations of obstructive sleep apnea syndrome before and after treatment with continuous positive airway pressure. Sleep 1992;15:S17-9.

71 Working Group on OSA and Hypertension. Obstructive sleep apnea and blood pressure. What is the relationship? Blood Pressure 1993 (in press).

72 Coccagna G, Mantovani M, Brignani F, Parchi C, Lugaresi E. Continuous recording of pulmonary and systemic arterial pressure during sleep in syndromes of hypersomnia with periodic breathing. Bull Physiopathol Respir 1972;8:1159-72.

73 Tolle FA, Judy WV, Yu PL, Markand ON. Reduced stroke volume related to pleural pressure in obstructive sleep apnea. $f$ Appl Physiol 1983;55:1718-24.

74 Garpestad E, Katayama J, Parker JA, Ringler J, Lilly J, Yasuda $\mathrm{T}$, et al. Stroke volume and cardiac output decrease at the termination of obstructive apneas. $\mathcal{F} A p p l$ Physiol 1992;73:1743-8.

75 Somers VK, Mark AL, Abboud FM. Sympathetic activation by hypoxia and hypercapnia-implications for sleep apnea. Clin Exp Hypertens 1988;10:413-22.

76 Ringler J, Basner RC, Shannon R, Schwartzstein R, Manning $\mathrm{H}$, Weinberger SE, et al. Hypoxia alone does not explain blood pressure elevations after obstructive apneas. F Appl Physiol 1990;69:2143-8.

77 Iwase N, Kikuchi Y, Hida W, Miki H, Taguchi $O$, Satoh $M$, et al. Effects of repetitive airway obstruction on $\mathrm{O}_{2}$ saturation and systemic and pulmonary arteria pressure in anesthetised dogs. Am Rev Respir Dis 1992 146:1402-10.

78 Leuenberger UA, Jacob EM, Sweer LW, Zwillich CW, Sinoway LI. Hypoxemia and surges of sympatheric activity mediate blood pressure oscillations in obstructive sleep apnea. Circulation 1992;86(Suppl):I-637.

79 Hedner J, Ejnell H, Sellgren J, Hedner T, Wallin G. Is high and fluctuating muscle nerve sympathetic activity in the sleep apnea syndrome of pathogenic importance for the development of hypertension. $\mathcal{F}$ Hypertension 1988;6:S529-31.

80 Becker MJ, Strohl KP, Thomas MD. Augmented peripheral chemoreflex gain in patients with obstructive sleep apnea syndrome. Circulation 1992;86(Suppl):I636.

81 Hedner J, Wilcox I, Laks L, Grunstein RR, Sullivan CE $A$ specific and potent pressor effect of hypoxia in patients with sleep apnea. Am Rev Respir Dis 1992 146:1240-5.

82 Sun M-K, Reis DJ. Evidence nitric oxide mediates the vasodepressor response to hypoxia in sino-denervated rats. Life Sci 1992;50:555-65.

83 Krieger J, Benzoni D, Sforza E, Sassard J. Urinary excretion of prostanoids during sleep in obstructive sleep apnea patients. Clin Exp Pharmacol Physiol 1991;18: $511-5$.

84 Ehlenz K, Herzog P, von Wichert P, Kaffarnik H, Pete $J H$. Renal excretion of endothelin in obstructive sleep apnea syndrome. In: Gautier C, Escourrou P, CurziDascalova, eds. Colloque INSERM. Vol. 217. John Libby Eurotext, 1991:403.

85 Lloyd HGL, Laks L, Grunstein R, et al. Plasma adenosine concentrations during episodes of obstructive sleep apnea. In: Jacobson KA, Daly JW, Manganiello V, eds. Purines in cellular signalling: targets for new drugs. New York: Springer Verlag, 1990:385-6.

86 Krieger J, Laks L, Wilcox I, Grunstein RR, Costas LJV, McDougall JG, et al. Atrial natriuretic peptide release during sleep in patients with obstructive sleep apnea before and during treatment with nasal continuous positive airway pressure. Clin Sci 1989;77:407-11.

87 Ehlenz K, Peter J, Kaffarnik H, Von Wichert $P$ Disturbances in the volume regulating hormone systems: a key to the pathogenesis of hypertension in obstructive sleep apnea? Pneumonologie 1991;45(Suppl 1) 239-45.

88 Jennum $P$, Borgesen SE. Intracranial pressure in obstructive sleep apnea. Chest 1989;95:279-83.

89 Fletcher EC, Lesske J, Qian W, Millar CC, Unger T. Repetitive, episodic hypoxia causes diurnal elevation of blood pressure in rats. Hypertension 1992;19:555-61.

90 Fletcher EC, Lesske J, Behm R, Millar CC, Stauss H, Unger T. Carotid chemoreceptors, systemic blood pressure and chronic episodic hypoxia mimicking sleep apnea. $\mathcal{F}$ Appl Physiol 1992;72:1978-84

91 Fletcher EC, Lesske J, Culman J, Miller CC, Unger T. Sympathetic denervation blocks blood pressure elevation in episodic hypoxia. Hypertension 1992;20:612-9.

92 Hedner JA, Ejnell H, Caidahl K. Left ventricular hypertrophy independent of hypertension in patients with obstructive sleep apnea. F Hypertension 1990;8:941-6.

93 Nattie EE, Bartlett D, Johnson K. Pulmonary hypertension and right ventricular hypertrophy caused by intermittant hypoxia in the rat. Am Rev Respir Dis 1978 118:653-7.

94 Malone S, Liu PP, Holloway R, Rutherford R, Zie A Bradley TD. Obstructive sleep apnoea in patients with dilated cardiomyopathy: effects of continuous positive airway pressure. Lancet $1991 ; 338: 1480-4$.

95 Verdecchia P, Schillaci G, Guerrieri M, Gatteschi C Benemio G, Boldrini $F$, et al. Circadian blood pressure changes and left ventricular hypertrophy in essential hypertension. Circulation 1990;81:528-36.

96 Wilcox I, Grunstein RR, Collins FL, Doyle JM, Kelly DT, Sullivan CE. Circadian rhythm of blood pressure in patients with obstructive sleep apnea. Blood Pressure 1992;1:219-22.

97 Stradling JR. Sleep apnoea and systemic hypertension. Thorax 1989;44:984-9.

98 Fletcher EC, DeBehnke RD, Lavoi MS, Gorin AB Undiagnosed sleep apnea in patients with essential hypertension. Ann Intern Med 1985;103:190-5.

99 Hoffstein V, Mateika J. Evening to morning blood pressure variations in snoring patients with and without obstructive sleep apnea. Chest 1992;101:379-84.

100 Isaksson H, Svanborg E. Obstructive sleep apnea syndrome in male hypertensives refractory to drug therapy. Nocturnal automatic blood pressure measurements an aid to diagnosis? Clin Exp Hypertens 1991;13:1195-212.

101 Coccagna G, Mantoveni M, Brignoni F, Pardu C, Lugaresi E. Tracheostomy in hypersomnia with periodic breathing. Bull Eur Physiopathol Respir 1981;8:117-28.

102 Guilleminault C, Simmons FB, Motta J, Cummiskey J, Rosekind M, Shroeder JS, et al. Obstructive sleep apnea syndrome and tracheostomy: long term follow up experience. Arch Intern Med 1981;141:985-8.

103 Burack B, Pollack C, Borowiecki B, Weitzman E. The 
hypersomnia-sleep apnea syndrome: a reversible major cardiovascular hazard (Abstract). Circulation 1977 56:17.

104 Jennum $P$, Wildschiotz G, Christensen NJ, Schwartz T. Blood pressure, catecholamines and pancreatic polypeptide in obstructive sleep apnea with and without nasal continuous positive airway pressure (nCPAP) treatment. Am $\mathcal{F}$ Hypertens 1989;2:847-52.

105 Mayer J, Becker H, Brandenburg U, Penzel T, Peter JH, v. Wichert P. Blood pressure and sleep apnea: results of long-term nasal continuous positive airways pressure therapy. Cardiology 1991;79:84-92.

106 Naughton M, Pierce R. Effects of nasal continuous positive airway pressure on blood pressure and body mass index in obstructive sleep apnoea. Aust NZ $7 \mathrm{Med}$ 1991;21:917-9.

107 Wilcox I, Grunstein RR, Hedner JA, Doyle JM, Kelly DT, Fletcher PJ, et al. Effect of short term treatmen with nasal continuous positive airway pressure on systemic blood pressure in obstructive sleep apnea. Sleep (in press).

108 Staessen JA, Fagard RH, Lijnen PJ, Thijs L, Van Hoof $\mathrm{R}$, Amery AK. Ambulatory blood pressure monitoring in clinical trials. F Hypertens 1991;9(Suppl 1):S13-9.

$109 \mathrm{He}$ J, Kryger M, Zorick F, Conway W, Roth T Mortality and apnea index in obstructive sleep apnea. Experience in 385 patients. Chest 1988;94:9-14.

110 Partinen M. Guilleminault C. Daytime sleepiness and vascular morbidity at seven-year follow-up in obstructive sleep apnea patients. Chest 1990;97:27-32.

111 Thorpy MJ, Lederich PS, Glovinsky PB, Burack B, Sher $\mathrm{AE}$, McGregor $\mathrm{P}$, et al. Nocturnal death in patients with obstructive sleep apnoea: the Montefiore long term follow up study. Sleep Res 1989;18:316.

112 Lavie P, Berger I, Yoffe N, Robin A-H, Chillag A Zomer $\mathrm{J}$, et al. Long-term morbidity and mortality of SAS patients. F Sleep Res 1992;1:(Suppl 1):131.

113 Hung J, Whitford EG, Parsons RW, Hillman DR Association of sleep apnea and myocardial infarction in men. Lancet 1990;336:261-4.

114 Koskenvuo M, Kaprio J, Telakivi T, Partinen M, Heikkilä K, Sarna S. Snoring as a risk factor for ischemic heart disease and stroke. $B M \mathcal{F}$ 1987;294: 16-19.

115 Palomaki H, Partinen $M$, Erkinjuntti T, Kaste $M$ Snoring, sleep apnea syndrome, and stroke. Neurolog 1992;42(Suppl 6):75-81.

116 Klingelhofer J, Hajak G, Sander D, Schulz-Varszegi M Ruther E, Conrad B. Assessment of intracranial hemodynamics in obstructive sleep apnea syndrome. Stroke 1992;23:1427-33.

117 Burwell C, Robin E, Whaley R, Bikelman A. Extreme obesity associated with alveolar hypoventilation: Pickwickian syndrome. Am f Med 1956;21:811-8.

118 Bradley TD, Rutherford R, Grossman RF, Lue F, Zamel N, Moldofsky H, et al. Role of daytime hypoxemia in the pathogenesis of right heart failure in the obstructive apnea syndrome. Am Rev Respir Dis 1985 131:835-9.

119 Whyte KF, Douglas NJ. Peripheral edema in the sleep apnea/hypopnea syndrome. Sleep 1991;14:354-6.

120 Fletcher EC, Schaaf JW, Miller J, Fletcher JG. Long term cardio-pulmonary sequelae in patients with sleep apnea and chronic lung disease. Am Rev Respir Di 1987;135:525-33.

121 Laks L, Krieger J, Podszus T. Pulmonary hypertension in obstructive sleep apnea: retrospective multicentre study. Am Rev Respir Dis 1992;145:A865.

122 Berthon-Jones $M$, Sullivan CE. Time course of change in ventilatory response to $\mathrm{CO}_{2}$ with long-term CPAP therapy for obstructive sleep apnea. Am Rev Respir Dis 1987;135:144-7.
123 Edwards LC, Daniels BK, Stanson AW, Sheedy PF, Shepard JW. The effect of transcutaneous electrical stimulation during wakefulness and sleep in patients with obstructive sleep apnea. Am Rev Respir Dis 1992; 146:1030-6.

124 Sullivan CE, Grunstein RR. Continuous positive airway pressure in sleep disordered breathing. In: Kryger $\mathrm{MH}$, Dement WC, Roth TP, eds. Principles and practice of sleep medicine. Philadelphia: Saunders, 1989:559-70.

125 Reeves-Hoche MK, Meck R, Zwillich CW. Long term $\vec{\supset}$ compliance with nasal continuous positive airway pressure (CPAP). Am Rev Respir Dis 1992;145:A169.

126 Sanders MH, Kern N. Obstructive sleep apnea treated $\stackrel{X}{.}$ by independently adjusted inspiratory and expiratory positive airway pressures via nasal mask: physiological $\stackrel{\rho}{\rightarrow}$ and clinical implications. Chest 1990;98:317-24.

127 Gugger M, Vock P. Effect of reduced expiratory pressure on pharyngeal size during nasal positive airway pressure $\overline{\bar{C}}$ in patients with sleep apnoea: evaluation by continuous $\frac{\rho}{\partial}$ computed tomography. Thorax 1992;47:809-13.

128 Piper AJ, Sullivan CE. Effects of short-term NIPPV in the management of patients with severe obstructive 5 sleep apnea and hypercapnia. Chest 1993 (in press).

129 Shepard JW, Gefter WB, Guilleminault C, Hoffman EA,. Hoffstein V, Hudgel DW, et al. Evaluation of the upper $\vec{A}$ airway in patients with obstructive sleep apnea. Sleep $\vec{\sigma}$
1991;14:361-71.

130 Riley RW, Powell NB, Guilleminault C. Maxillofacial surgery and obstructive sleep apnea. A review of 80 . surgery and obstructive sleep apnea. A review of 80.
patients. Otolaryngol Head Neck Surg 1989;101:353-61.

131 Ikematsu T. Study of snoring. 4th report: therapy. $\mathcal{f}$ fap Otorhinolaryngol 1964;64:434-5.

132 Hendriks JC, Kline LR, Kovalski RJ, O'Brien JA, ㄱ Morrison AR, Pack AI. The English bulldog: a natural model of sleep-disordered breathing. 7 Appl Physiol 음 1987;63:1344-50.

133 Fujita S, Conway W, Zorich F, Roth T. Surgical cor- $\vec{c}$ rection of anatomic abnormalities in obstructive sleep apnea syndrome: uvulopalatopharyngoplasty. Otolaryngol Head Neck Surg 1981;89:923-34.

134 Sullivan CE, Berthon-Jones M, Issa FG, Eves L. Cै Reversal of obstructive sleep apnoea by continouous. $\omega$ positive airway pressure applied through the nose. Lancet $1981 ; \mathbf{i}: 862-5$.

135 Rodenstein DO. Assessment of uvulopalatopharyngoplasty for the treatment of sleep apnea syndrome. Sleep $\bar{O}$ 1992;15(suppl):S56-62.

136 Larsson H, Carlsson-Nordlander B, Svanborg E. Long-응 time follow-up after UPPP for obstructive sleep apnea syndrome. Acta Otolaryngol (Stockh) 1991;111:582-90. $\overrightarrow{\vec{O}}$

137 Harmon JD, Morgan W, Chaudhary B. Sleep apnea: morbidity and mortality of surgical treatment. South Med f 1989;82:161-4.

138 Walker EB, Frith RW, Harding DA, Cant BR. Uvulatopharyngoplasty in severe idiopathic obstructive Uvulatopharyngoplasty in severe idiopathic obst
sleep apnoea syndrome. Thorax 1989;44:205-8.

139 Shepard JW, Thawley SE. Evaluation of the upper air-으 way by computed tomography in patients undergoing uvulopalatopharyngoplasy for obstructive sleep apnea. Am Rev Respir Dis 1989;140:711-6.

140 Launois SH, Feroah TR, Campbell WN, Issa FG, Morrison D, Whitelaw WA, et al. Site of pharyngealo narrowing predicts outcome of surgery for obstructive 3 sleep apnea. Am Rev Respir Dis 1993;147:182-9.

141 Polo O, Brissaud L, Sales B, Besset A, Billiard M. Partial 윽 upper airway obstruction in sleep after uvulopalato- $\rightarrow$ pharyngoplasty. Arch Otolaryngol Head Neck Surg 1989, 115:1350-4.

142 Plowman L, Lauff DC, Berthon-Jones M, Sullivan CE. N Waking and genioglossal muscle responses to upper air-o way pressure oscillation in sleeping dogs. 7 Appl Physiol N 1990;68:2564-73. 